\title{
Assessment of inhibitors with chromogenic substrates
}

\author{
ZBIGNIEW S LATALLO \\ From the Institute of Nuclear Research, Warsaw, Poland
}

Blood plasma contains a number of proteins capable of inhibiting the activation of plasminogen and the action of plasmin. Except for urokinase, the nature and action of plasminogen inhibitors are not yet fully understood. Inhibitors of plasmin, on the other hand, are fairly well defined and their clinical significance recognised.

Although there are a number of plasmin inhibitors in plasma-for example, $\alpha_{1}$-antitrypsin, inter- $\alpha$ inhibitor, antithrombin III, and $\mathrm{C} 1$-inactivatoronly two, $\alpha_{2}$-antiplasmin and $\alpha_{2}$-macroglobulin, appear to be important in vivo. $\alpha_{2}$-Antiplasmin (see D Collen at page 24) is a specific inhibitor of plasmin which binds the enzyme instantly and irreversibly in a stoichiometric manner $(1: 1)$. Its molar concentration in plasma is about $65 \%$ of that of plasminogen. Thus on complete activation of plasminogen in plasma only two-thirds of the resulting plasmin is inactivated by $\alpha_{2}$-antiplasmin. The remainder is taken care of primarily by $\alpha_{2}-$ macroglobulin. This inhibitor differs greatly from $\alpha_{2}$-antiplasmin. It is present in plasma in a much higher concentration, has very broad specificity (binds most of the proteases), and has a progressive action.

It is generally accepted that the $\alpha_{2}$-macroglobulinenzyme complex is formed in two stages-firstly, there is a proteolytic cleavage of $\alpha_{2}$-macroglobulin by the enzyme and, secondly, a conformational change of the modified inhibitor which traps the enzyme. Owing to steric hindrance, access of high molecular weight substrates to the enzyme is prevented and the complex is practically inactive towards natural protein substrates. However, it retains its activity for small synthetic substrates. Since the access of other inhibitors to the complex is also dependent upon their size this activity cannot be blocked effectively by such commonly used inhibitors of plasmin as soya bean trypsin inhibitor and aprotinin.

Assay of both $\alpha_{2}$-antiplasmin and $\alpha_{2}$-macroglobulin has been greatly facilitated by new types of synthetic peptide compounds called chromogenic substrates. Several such substrates, composed of three amino-acid peptides with a para-nitroaniline group attached to the C-terminal end, have been synthesised. Depending on their amino-acid composition, these substrates are highly sensitive to plasmin, thrombin, factor $\mathrm{X}^{\mathrm{a}}$, urokinase, kallikrein, and other proteases. A schematic reaction of plasmin with a substrate S-2251 (Kabi, Stockholm) designated for its assay is:

$$
\stackrel{\substack{\text { Plasmin } \\ \downarrow}}{\text { H-D-Val-Leu-Lys-pNA } \rightarrow \text { H-D-Val-Leu-Lys-OH + pNA. }}
$$

Owing to the difference of light absorption between the colourless substrate and the intensively yellow pNA, the reaction can be easily followed by measuring the amount of product released with time using a spectrophotometer at $405 \mathrm{~nm}$.

The main advantages of these chromogenic substrates compared with previous ones (fibrin, casein, synthetic arginine esters, BApNA, etc.) are: (1) high stability, which enables them to be kept in solution at room temperature for several days without spontaneous hydrolysis; (2) high sensitivity, comparable to or exceeding routine clotting and fibrinolytic tests; (3) easy and rapid performance, so that assays can also be adapted for automatic analysers; (4) only small amounts of sample needed for testing; most assays need 2-20 $\mu \mathrm{l}$ plasma.

As with any other small synthetic substrates there are problems of specificity, especially when enzyme activity in biological material is dirictly assayed. Results may be erroneous when the sample contains more than one active enzyme. However, with assays of inhibitors this problem is less acute since any spontaneous activity present can be identified by running a proper control without the enzyme and the enzyme itself can then be defined and standardised.

The principle of the $\alpha_{2}$-antiplasmin assay in plasma is very simple. Since the $\alpha_{2}$-antiplasminplasmin complex is totally inactive the assay consists in measuring the amount of active plasmin remaining after a very short incubation of the test plasma with the enzyme. Several technical procedures have been based on this principle. One was described in detail together with a block of tests for measuring other 
components of the plasma fibrinolytic system. ${ }^{1}$ This block of tests also includes an $\alpha_{2}$-macroglobulin $\left(\alpha_{2} M\right)$ assay. It is a modification of a method proposed by Ganrot ${ }^{2}$ in which $\alpha_{2} \mathrm{M}$-trypsin complex was assayed using BApNA as a substrate.

The $\alpha_{2} \mathrm{M}$ assay is based on the fact that the $\alpha_{2} \mathrm{M}$-plasmin complex retains its activity towards the chromogenic substrates. Hence the procedure is in three steps: (1) incubating plasmin (in excess) with plasma sample, which results in the formation of the $\alpha_{2}$ M-plasmin complex; (2) inhibiting the remaining free enzyme with aprotinin; and (3) measuring the $\alpha_{2} \mathrm{M}$-plasmin activity using chromogenic substrate S-2251. A straight linear relationship between the activity and $\alpha_{2} \mathbf{M}$ concentration allows a calibration curve to be made from normal pooled plasma. Our recent studies of the interaction of $\alpha_{2} \mathrm{M}$ with plasmin indicate that the use of soya bean trypsin inhibitor instead of aprotinin increases the reproducibility of this assay since the latter partly inhibits the $\alpha_{2} \mathrm{M}$-plasmin complex in a progressive manner. ${ }^{3}$

Figures 1 and 2 illustrate the usefulness of the $\alpha_{2}$-antiplasmin assay. Figure 1 shows the changes in $\alpha_{2}$-antiplasmin in plasma during combined treatment with streptokinase and plasminogen. Interesting comparisons of the $\alpha_{2}$-antiplasmin concentrations in the plasma of two patients treated with the same standard dose of urokinase are shown in Fig. 2. A definite difference in reaction to the drug was also seen in changes in plasminogen concentration (unpublished results).

These results cast some doubt on the validity of a standard dose regimen and suggest a need to compare clinical effectiveness and the pattern of the

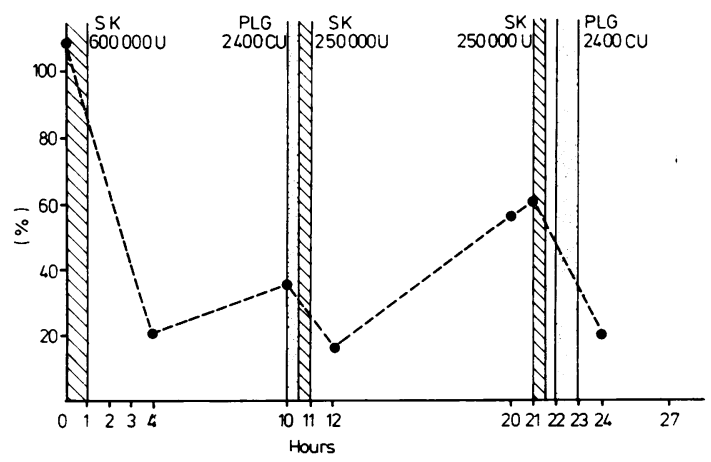

Fig. 1 Changes in $a_{2}$-antiplasmin concentrations in plasma of patient on intermittent therapy with streptokinase $(S K)$ and plasminogen (PLG).

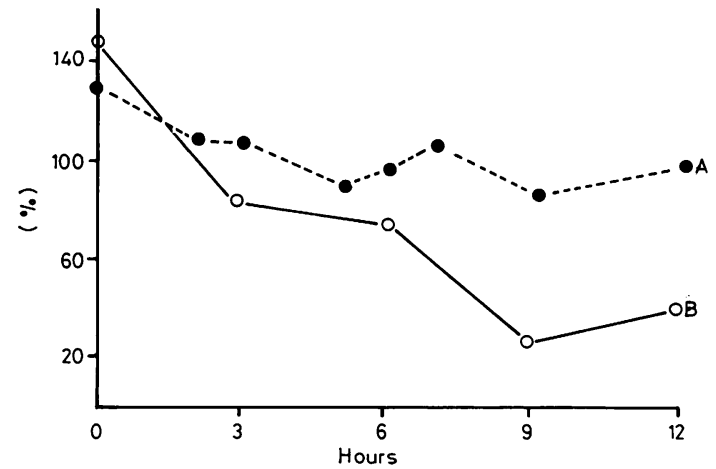

Fig. 2 Changes in $\alpha_{2}$-antiplasmin concentrations in plasma of two patients treated with a standard dose of urokinase (4000 CTA $\mathrm{U} / \mathrm{kg} / \mathrm{h}$ ) given as continuous intravenous infusion for 12 hours.

plasma fibrinolytic system in urokinase therapy. Studies of changes in $\alpha_{2} M$ concentration during streptokinase therapy show that it decreases slowly. 4 The full meaning and importance of these changes need further study. We found ${ }^{3}$ that plasmin is bound to the complex with $\alpha_{2} \mathbf{M}$ much faster than thrombin and the formation of $\alpha_{2} \mathrm{M}$-factor $\mathrm{X}^{\mathrm{a}}$ complex is very slow. Since the $\alpha_{2}$-antiplasmin has no counterpart in antithrombins in neutralisation rate these findings might explain why a state of hypercoagulability, including diffuse intravascular coagulation, is so often encountered whereas primary activation of fibrinolysis is seldom, if ever, seen.

This work was supported by a Polish Government grant PR-6:1F-8H-4M.

\section{References}

${ }^{1}$ Latallo ZS, Teisseyre E, Lopaciuk S. Assessment of plasma fibrinolytic system with use of chromogenic substrates. Haemostasis 1978;7:150-4.

${ }^{2}$ Ganrot PO. Determination of $\alpha_{2}$-macroglobulin as trypsin-protein esterase. Clin Chim Acta 1966;14: 493-501.

${ }^{3}$ Dudek-Wojciechowska G, Latallo ZS. Role of $a_{2}$ macroglobulin in the inhibition of clotting. International Symposium and Workshop on Structure, Biochemistry and Function of Antithrombin III, November 1979, Homburg Saar.

${ }^{4}$ Latallo ZS, Teisseyre E, Lopaciuk S. Evaluation of a fibrinolytic profile of plasma using chromogenic substrates. In: Scully MF, Kakkar VV, eds. Chromogenic peptide substrates. London: Churchill Livingstone, 1979:262-8. 